\title{
An Overview of Human Resource Development Programmes in Indian Industries
}

\author{
Dr. V. K. Jain \\ Associate Professor \& Head, Department of Commerce, G.M.N. College, Ambala Cantt., Haryana (India)
}

\begin{abstract}
Development of Human Resources is being given due importance by all the organizations as it aims at developing all the employees of an organization in a planned manner to acquire, sharpen and apply their existing capabilities as well as their inner potentials. HRD is a total system in which its various mechanisms are embedded together to act as an integrated unit. No sub-system can work in isolation. The researches show that the working of each sub-system has its impact on other sub-systems e.g. Performance appraisal is basis for assessing training needs, career planning etc. Training is useful tool for increasing individual efficiency. It is also a part of employee welfare and is used for promotions.

Implementing these HRD sub-systems helps in developing a climate in the organization where the people collaborate with each other; respect and trust others and work as a team. This, in turn, develops a highly positive and motivated workforce which enables the organization to achieve its goals.

Keeping the significance of Human Resources in an organization in mind, the present study has been undertaken. The study explores the linkages in human resource development mechanisms and HRD climate variables resulting from it.

The results have been extracted mainly on the basis of Secondary data However, personal experience of the researcher in few pharmaceutical industries and conversation with the authorities of the companies has been included at appropriate places.
\end{abstract}

Keywords: HRD Climate, Potential Appraisal, Performance Appraisal, Counseling, Effectiveness, Rewards, Training.

\section{Introduction}

Growing needs of growth and expansion, on the one hand and increasing efficiency and productivity to combat competition, on the other, emphasize on an increase in creativity and autonomy of the people in the society. The expectations of the people are changing fast. They want to be dealt with and respected as human beings and are to be provided opportunities for the fuller expression of their potentials. HRD helps the organization not only in the attainment of its objectives but also provides opportunities to the people to fulfill their requirements, and get maximum job satisfaction. Human resources are the most valuable of all the resources whether potential or existing in any organization and the most vital for the successful achievement of its objectives. The contribution they make may not be arithmetically calculable but it is indeed highly significant in achieving the organizational goals.

Human Resource Development (HRD) is, therefore, gaining significance in the success of any industrial organization. The organizations today have realized that it is the contribution of the human resources which helps them to grow, proper and attain their objectives. Human resource development (HRD) aims at developing all the employees of an organization in a planned manner not only to acquire and apply their existing capabilities but also their inner potentials and helps in building a climate with strong interpersonal bonds which helps the organization to achieve its goals.

\subsection{HRD Concept}

Human Resource Development (HRD) is a continuous process to ensure the development of employee competencies, dynamism, motivation and effectiveness in a systematic and planned way. In the organizational Context HRD refers to the improvement in capacities and capabilities of the personnel in relation to the needs of the organization. It involves the creation of climate where human knowledge, skill, capabilities and creativity can bloom. It involves the use of processes through which the employees of the organization are prepared to give their best for the achievement of corporate objectives and bring optimal effectiveness in their jobs as well.

Rao, T. V. (1991) has stated that: "Human Resource Development (HRD), in organizational context, is a process by which the employees of an organizational are helped in a continuous and planned way, to a) acquire or sharpen capabilities required to perform various functions associated with their present or future expected roles; b) develop their general capabilities as individuals and discover and exploit their own inner potentials for their own and/or organizational development purposes; and c) develop an organizational culture in 
which superior-subordinate relationship, teamwork, and collaboration among the sub-units are strong and contribute to the professional well-being, motivation and pride of the employees."

Rao (1991) further explained that HRD aims at helping people to acquire competencies. The process of acquisition can be facilitated by HRD mechanisms (instruments/sub-systems) like performance appraisal, training, OD, feedback and counseling, career development, potential development, job rotation and rewards.

In his book Handbook of Human Resources Development, Nadler (1984), has defined Human Resource Development as organized learning experiences in a definite time period to increase the possibility of improving job performance and growth. Explaining the various parts of the definition, Nadler defined organized learning experiences as intentional learning structures with objectives, a plan and provision for evaluation. Defining the term 'A definite time period', he has stated it as agreed upon and identifiable point at which a particular phase of learning has been completed. Further the term 'To increase the possibility of' means HRD would provide the learning but can not guarantee that learning experience will change performance. While explaining 'Improving job performance' he stated that the most organization sponsored HRD aims at affecting job performance. 'Growth' helps individuals to grow so that they will be ready to move with the organization. According to Nadler, HRD encompasses these learning areas, improving performance on an individual's present job, preparing individual for an identified job in near future and general growth 'Not related to specific job'.

\subsection{HRD Objectives}

The major objective of HRD is to prepare employees to cope with functional complexities and facilitate integration of changes. The changes may be social, economic and technological. The people development process is, therefore, the synthesis of efforts on two fronts - preparing individuals for technological competence and psychological acceptance for willing participation in change implementation. The focus of HRD has to be more on conditions of the organizational climate (Rao, 1992). In fact, HRD aims to achieve multiple goals as follows:

\subsubsection{Employee Competency Development}

$\mathrm{HRD}$ also helps people to perform the roles or functions which may be assigned to them in future and tries to develop their potentials for future likely jobs/roles in the organization by enabling them to develop their competencies including knowledge, attitudes and skills to perform different tasks or functions and combat the changes occurring in the environment, organizational priorities, goals and strategies, technology, new knowledge base, new challenges etc.

\subsubsection{Employee Motivation Development}

HRD aims at developing the motivation of employees to maximum possible extent so that they can become dynamic contributors to organizational goals as motivation is a commitment to the job, work and the organization. It is also the desire to make things happen. Without motivation employees are not likely to give their best. Motivation is influenced by various factors such as one's own needs, personality and habit patterns, supervisor's style and behaviour, personnel policies, organizational culture and environment, career opportunities and reward mechanisms.

\subsubsection{Organizational Climate Development}

$\mathrm{HRD}$ also aims at climate development. A healthy organizational climate helps in

utilizing and enhancing employee competencies and developing employee motivation. A healthy climate is one which is characterized by:

a) Pro-activity: Employees are action oriented and willing to take initiative.

b) Openness and risk taking: Employees feel free to express their ideas and are willing to take risks, experiment with new ideas and new ways of doing things.

c) Collaboration: Employees collaborate with each other and have a feeling of belongingness towards the group and the organization.

d) Trust and authenticity: Employees and work groups trust each other and can be relied upon to do whatever they say they will do.

e) Confrontation: Employees face problems and issues without hiding or avoiding them.

f) Autonomy: Employees have some freedom to act independently within the boundaries of their role/ job (Rao, 1991).

The elements of HRD climate can be grouped into three broad categories - general climate, OCTAPAC culture and HRD mechanisms. The general climate items deal with the importance given to HRD in general by the top management and line managers. The OCTAPAC items deal with the extent to which openness, confrontation, trust, autonomy, pro-activity, authenticity and collaboration are valued and promoted in the organization. 
The items dealing with HRD mechanisms measure the extent to which these mechanisms are implemented seriously. HRD climate can be developed if top management has a strong belief in the capabilities of its people and its policies show high concern for employees. HRD sub-systems and increasing effectiveness also help in building HRD climate.

\section{Statement of the Problem}

'Human Resource' are the most important and valuable resource for every organization. It is the competent and motivated workforce that makes things happen and helps the organization to achieve its goals. In fact, effective employees contribute to the effectiveness of the organization. Organizations, therefore, need to contribute to the dynamism, competency, motivation, efficiency and effectiveness of the employees continuously. Human Resource Development is a continuous process which ensures the employee development in a systematic and planned manner. It aims at developing the competencies of the employees on the one hand and building organizational culture on the other, to utilize these competencies and contribute to the organizational growth.

Keeping the significance of Human Resources in an organization in mind, the present study has been undertaken. The study explores the linkages in human resource development mechanisms generally applied in the organizations and HRD climate variables resulting from it, affecting the development of the employees of the organization and their impact on organizational efficiency and effectiveness. The researches undertaken in the past clearly indicate that there exists a relationship among the HRD mechanisms, HRD climate variables and HRD outcome variables. The efforts have been made to explore these relationships.

\subsection{Objectives of the Study}

The study seeks to answer the following questions:

1. Whether the Indian Organizations attach significance to the Human Resources and the top management is concerned about it?

2. What are the main HRD subsystems being applied in these organizations in India?

3. Whether there exist HRD climate variable in these organizations?

4. To what extent the HRD variables contribute to the development of organizational growth, productivity and effectiveness?

\subsection{Methodology}

The data and material has been collected from various books and journals on HRD. Although the secondary data has been used for the study, the researchers have also used their experiences in few pharmaceutical companies and personal interaction with the officials of these companies on the problem stated above.

The analysis has been made on the basis of the studies undertaken in the past on different aspects of human resource development. The various mechanisms applied by the organizations have been analyzed on the basis of these researches. Similarly, the HRD climate variables and their impact on organizational effectiveness have been analyzed on the basis of available research material. No specific statistical tools have been used for the analysis. However the data has been compiled and analyzed in a manner to provide significant results.

\subsection{Significance of the Study}

The study is of great significance to the academicians and researchers as it not only strengthens the theoretical base of HRD but also tries to analyze the relationships among the various HRD mechanisms, there linkage with HRD climate variables and HRD outcome variable. The analysis provides an insight into the overall development climate building up for growth and effectiveness. It will help the researchers to undertake future research on these aspects.

\subsection{Limitations}

As the study is based on secondary data taken from books/ journals, it has limited impact in view of the present environment which is changing very fast. Further, results need to be authenticated in view of globalization and liberalization of the world economy, new practices and new methods being applied in the organizations

\section{Framework of HRD}

Human Resource Development is a continuous process that helps an organization to develop competent, dynamic and growth oriented people. But the competence and dynamism can be created when the organization has a developmental climate. HRD is developed through HRD mechanism which enables HRD Climate development. A good developmental climate results organizational effectiveness and ultimate growth 
of the organization. Figure-1 presents a framework of relationship in HRD mechanisms, HRD climate variables and HRD outcome variables in our industries.

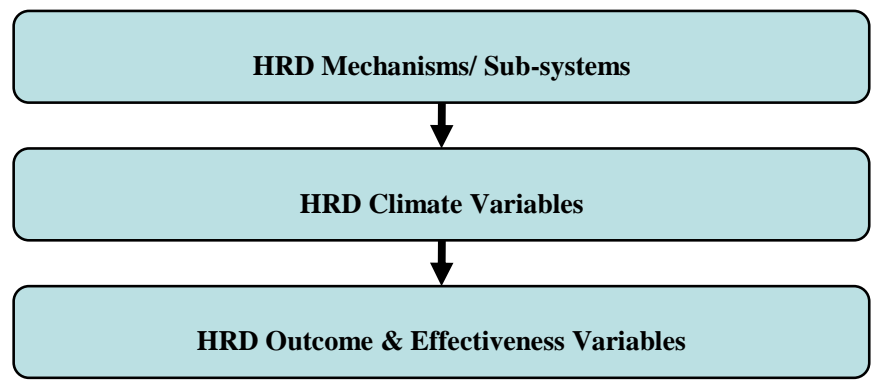

Figure-1: Linkages in HRD Mechanisms, HRD Climate and HRD outcomes

\subsection{HRD Mechanisms/ Sub-Systems}

In order to develop the capabilities of each employee in the organization and collaboration among the different units of the organization, HRD sub-systems or mechanisms are applied in every organization.

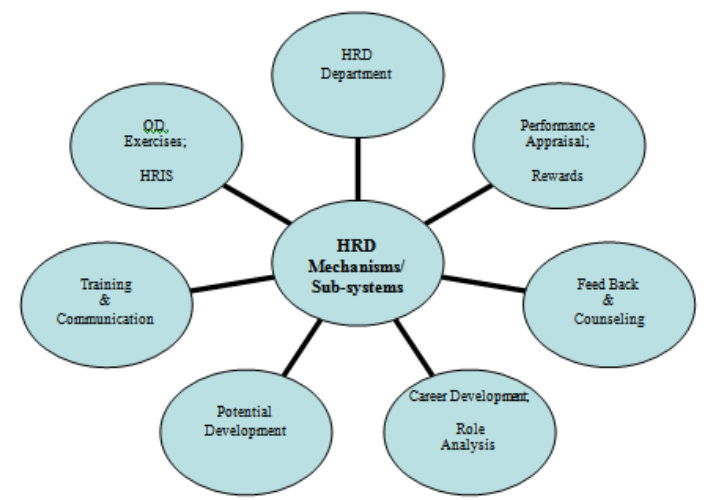

Figure-2: HRD Mechanisms/ Sub-systems

Some of the HRD mechanisms including performance appraisal, potential development, feedback and counseling, training and communication, O.D., Human Resource Information System etc. are practiced in Indian Industries. These mechanisms have been shown in figure 2.

\subsection{HRD Climate Development Variables}

The HRD mechanisms facilitate in the development of HRD climate in the organization.

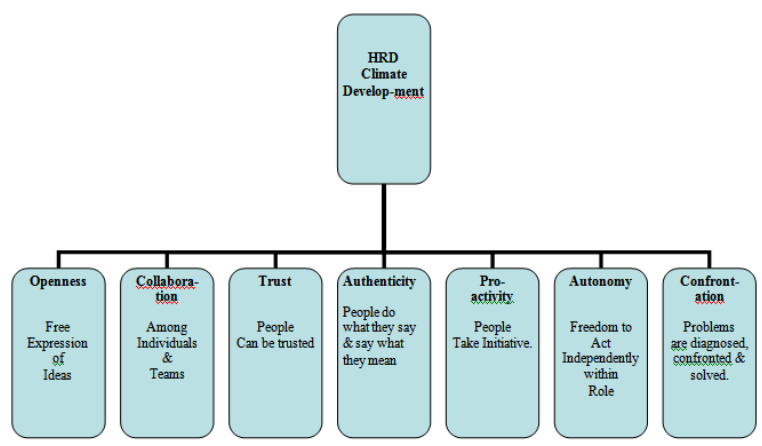

Figure-3: HRD Climate Variables

Rao has highlighted the development of OCTAPAC culture in the organization through the practice of HRD mechanisms. OCTAPAC culture means a culture being developed in the organization where there is an atmosphere of openness, confrontation, trust, autonomy, pro-activity, authenticity and collaboration. The HRD climate variables have been presented in Figure-3.

The figure shows that HRD facilitates free expression of ideas, team building, freedom to act independently, initiative taking and problem-solving. They help in achieving the goals of the organization. 


\subsection{HRD Outcomes Variables}

The existence of good HRD climate in an organization surely results in the growth of the organization in terms of Higher Productivity, Lesser Cost, more profit and better image. Besides it helps in developing more competent people, increasing job satisfaction, team work and respect for each other. It also helps in better utilization of Human Resources and better organizational health. Various HRD outcome variables in the organization have been shown in Figure-4.

The framework indicates that organizational effectiveness to a great extent are affected by competent, committed, satisfied and dynamic people as they are likely to do better as compared to other organizations which do not have such people. Similarly an organization that has better HRD climate and processes is likely to be more effective than any other organization which doesn't have them. These HRD climate variables are generated largely by the use of HRD mechanisms or sub-systems by the organization.

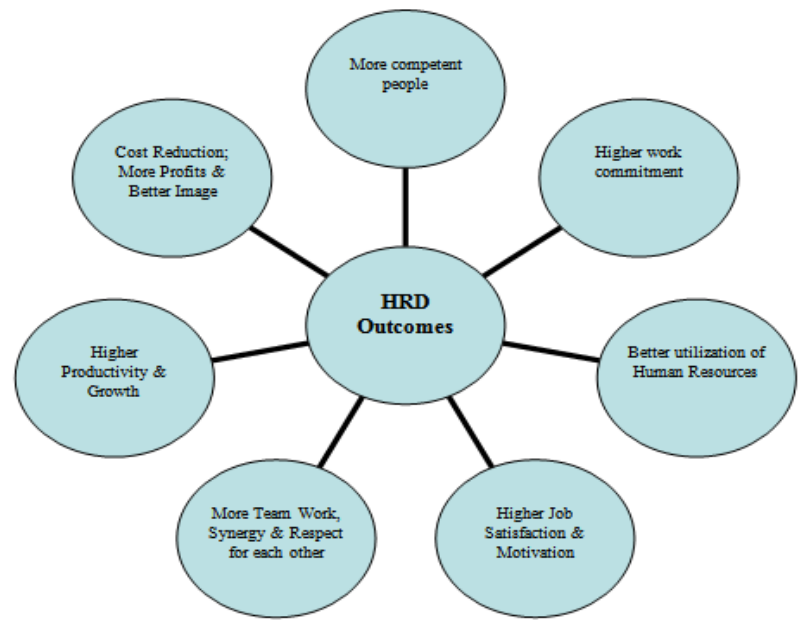

Figure-4: HRD Outcome Variables

\section{HRD Practices in Indian Industries}

The HRD aims at helping people to sharpen their capabilities and acquire competencies. The process of acquisition of capabilities and competencies is facilitated by HRD mechanisms like performance appraisal, training, OD, feedback and counseling, potential development, job-enrichment, rewards etc. These HRD subsystems help in developing a positive HRD climate indicated by openness, confrontation, trust, authenticity, pro-activity, autonomy and collaboration. It helps in developing competent, committed and satisfied workforce, an atmosphere of trust and authenticity and teamwork in the organization which ultimately helps the organization to achieve its goals of higher productivity and growth; efficiency and effectiveness; and more profit and better image.

Accordingly, an effort has been made to study the HRD sub-systems and HRD climate in Indian Industries. No program or no policy can be effective unless the top management is committed to implement it whole-heartedly. The existence of HRD department in an organization is therefore a pre-requisite for the success of entire HRD system. Keeping all these factors in mind the chapter is divided in three parts:

a) HRD Sub-systems practiced by Indian Organizations

b) HRD Climate in these organizations

c) HRD Outcomes

\subsection{HRD Sub-Systems Practised by Indian Organizations}

The following HRD sub-systems are generally practiced in Indian organizations:

\section{HRD Departments}

HRD has been evolved as a separate function in early 90's. Separate HRD department is expected to contribute to the development of HRD processes. Rao and Abraham (1984) on the basis of his survey of 53 companies found that 30 per cent of them had maintained a separate HRD department. In other, 38 per cent the HRD function was operational as a part of the personnel department. Similarly, a study of 14 large public and private sector organizations by Rao (1986) indicated that only three of them did not have separate HRD departments. The same was confirmed by Jain (1996) in his study of major Public Sector Organizations in India. Further, Jain (2013) made a study of the Pharmaceutical firm and found that HRD department existed in that company. As 
per the information gathered from the web, it has been found that some of the pharmaceutical companies like Ranbaxy, Panecea, Abbott etc. also have separate HRD departments.

It appears that HRD departments exist in almost all large public and private sector organizations. It also indicates that the top management believes in the development of its human resources as its assets.

\section{Performance Appraisal}

Performance appraisal is probably one of the oldest yet most imperfect of managerial activities. It is a formal exercise which is necessary for all important decisions relating to such as placement and promotion, remuneration and reward. It also helps in long-term manpower planning organization development. Gordon, L. Simpson (2004), in his article "Performance Appraisal- an Important Managerial Responsibility" viewed performance appraisal as a beneficial process in HRD. He opined that Performance Appraisal should be accepted as a normal management responsibility to review the performance of all employees and discuss its results with them regularly.

A study conducted by Rao and Abraham (1986) indicates that in the 53 organizations surveyed by them, about 27 per cent of them have mainly development as the objective of performance appraisal. While 49 per cent emphasize on development and control of employee behaviour as objective of Performance Appraisal. There are three main procedures for making relative performance judgments, namely, paired comparisons, ranking and forced distribution. Besides, modern methods including graphic trait rating scales, check lists, critical incidents and behavioral anchored rating scales are also used for Performance appraisal.

Jain (2013) in his study shows that Performance Appraisal is used as HRD sub-system in BHEL and NFL. Grading and Ranking method was found to be widely used. Further, performance appraisal was found to be quite useful in improving individual and organizational efficiency and productivity.

A survey of 87 Pune-based by Anandram (1987) revealed that only 15 per cent of small and medium scale have performance appraisal. Study of 60 companies by Basu (1985) showed that about 83 per cent of companies were using formal systems of Performance Appraisal. Many organizations are use the appraisal data for work planning, strengthening superior-subordinate relationship etc. Similar results have been indicated in the study conducted by Jain (2014). Study by the researcher shows that a number of firms in Pharmaceutical industry are using modern methods of appraisal like 360 degree feedback etc.

It can be concluded that the Indian organizations are using appraisal systems for various objectives indicated above. Many organizations are revising their appraisal systems to make it more effective.

\section{Potential Appraisal}

In most Indian organizations, Pareek and Rao (1981), admit that most organizations use performance appraisal form to collect data on the potential of the employee. But past performance is not necessarily an indication of future potential. In fact, the identification of an individual's potential is probably the most difficult aspect of performance assessment. Jain (1996) in his study of HRD Practices in Indian Industries affirms that potential appraisal is not being used in its true sense in BHEL and NFL.

The researchers on the basis of various studies made in MNCs and other pharmaceutical companies as well as public sector organizations found that these organizations also do not use Potential Appraisal as a HRD sub-system in their organizations. Potentials are, however, examined on the basis of Performance Appraisals, job descriptions and employees' disclosures.

The surveys conducted by Rao (1982) and Rao and Abraham (1986) indicate that systematic potential appraisal is not followed in Indian organizations. Even organizations like Larsen \& Toubro are still in the process of establishing such systems.

It can be inferred that potential appraisal is still to be implemented in its true spirit by most of the organizations.

\section{Feedback and Counselling}

Counselling helps to strengthen the superior-subordinate relationships and enables employees to recognize their strengths and weaknesses. In many organizations the counselling is used to provide feedback in a threatening way or warn them not to repeat unsatisfactory behavior on their part. This is not right. Giving feedback, giving warnings, enforcing norms etc. are part of a manager's job but Counselling helps an employee to recognize their potentials and prepares him for his own development.

The survey by Rao and Abraham (1986) indicate that 41 out of the 53 (that is, 80 per cent) companies surveyed, require their executives to counsel their subordinates, The high percentage of organizations requiring their executives to counsel their subordinates is a very deceptive indicator of the practice of counselling. They pointed out that these organizations do not really have performance counselling. Rather, a sizeable number of organizations use counselling for more than one purpose.

Contrarily, the research made by the researcher, indicates that many of the companies are now using this sub-system more effectively to improve employee performance and attain organizational goals. 


\section{Training}

Training is the most important sub-system of HRD as it directly contributes to the development of human resources. Therefore, it is also the most widely used HRD mechanism in the country. Some organizations use training and HRD synonymously. Training is, therefore, essential because of the changes in technology, managerial and behavioural dimensions. Training needs are to be identified form the other subsystems of HRD such a performance appraisal, performance analysis and counselling and potential appraisal. In an article - a critical look at Training in Industry, D'Souza (1986) contends that the return of investment on training is very poor, because people are sent for training in many industries as "fringe benefits" and very little is being done to make use of the learning once people return from a training programme. Similar conclusions were arrived at by Rao and Abraham (1986) in a study of HRD climate of 42 organizations. The respondents replied in negative to the questions of utilizing opportunity to try out what they have learned, and sponsoring employees on the basis of 'genuine training needs'.

A study made by Jain (1996) in BHEL and NFL also indicated that the two public sector organizations use Training as HRD sub-system in their organizations but training needs are not always analyzed before selecting employees for training. Again, a query from the various organizations by the researcher revealed that they are providing training to their employees for improving their performance, updating their skills and to take up new responsibilities at the time of promotions. But the respondents were of the opinion that analyzing the employees need for training and providing them opportunity to apply the new skills are not properly followed.

It can be stated that the training, although, widely practiced sub-system of HRD needs to be integrated and implemented properly.

\section{Career Planning And Development}

Career advancement is the prime motivating factor for most managers. They want to know where they would be going in the organization alter three, five, 10 years from their joining. A meaningful career planning system should be based on potential appraisal. Career planning and development can become an effective tool for development of the employee and a key factor in the HRD system (Philip, 1987)

The inquiry made by the researcher shows that the large organizations like Ranbaxy make career development plans for their employees but the medium-sized organizations of Scientific goods industry and some pharmaceutical firms do not have formal career development plans for their employees.

In fact, both performance appraisal and career development have potential for developing human resources. Employee potential can be increased by linking them together to meet the needs of both individual employees and the organization. It is, therefore, apparent that the organizations willing to upgrade the competencies of their human resources must pay attention to the development of these sub-systems.

\section{Rewards}

Rewards play an important role in setting up a development oriented climate because it has a acts as motivating force for those who are good performers. Singh (1983) says that salary is not enough to produce an adequate impact on enhancement of performance, reduction of absenteeism and retaining of skilled employees. To attract competent persons from outside, it is also increasingly felt that reward systems should help attracting the individuals with requisite the knowledge, ability and talents and retain productive employees in the organization as precious assets.

The rewards should be adopted as HRD sub-system in every organization. The rewards in the form of appreciation letters, citations and higher responsibilities can make positive impact.

Almost all the pharmaceutical organizations, organizations in public and private sector (Jain, 1996) and small and medium sized firms of scientific goods industry give rewards to their employees for their good performance. The researcher feels that the rewards should be linked with performance to help the organization to attain its goals.

\section{Organization Development}

Organizations are like individuals and families. They need people who can solve their problems. They need to develop a system where people learn to organize themselves to cope with the demands of a changing environment

Pareek (1975) defines OD as a planned effort, initiated by process specialist(s) to help an organization develop its diagnostic skills, coping capabilities, linkage strategies in the form of temporary and semipermanent systems, and a culture of mutuality. Organization development is a long-range effort to introduce planned change which helps in increasing organizational effectiveness.

Rao and Abrahm (1986) in their survey of 53 organizations reported that 44 per cent of them seem to have some OD activity actually going on and most of them seem to focus on "team building" and "role clarity" exercises. Other OD activities include interpersonal sensitivity, personal growth and stress management. 
In BHEL and NFL, Jain (1996) has explored that HRD helps in OD through conflict management and by increasing co-operations between inter-dependent units. The respondents agreed that $\mathrm{OD}$ is helpful in increasing individual and organizational efficiency and productivity. Many MNCs are also found to be using OD interventions for conflict management, role negotiations, increasing team spirit etc.

On the whole, there is an encouraging upward trend in using OD in Indian organizations. Team development and other OD activities mentioned above will bring about a change of culture-healthy and development-oriented, which may nurture development of human resources.

\section{Human Resources Information System}

In an age of rapid technological changes, automation and computerization it has become necessary that information on human resources is stored for various purposes. A human resources information system (HRIS) can be defined as "an information system that monitors, controls and influences the movement of human beings from the time they indicate their intention to join an organization till they separate from it (Chandrasekhar, 1986).

It was ascertained by the researcher that many pharmaceutical companies are using human resources information system (HRIS) in their organizations as per their needs. Many organizations are using job portals, employee portals, e-recruitment, e-learning, e-training, HR software which are creating transparency and are building an atmosphere of trust and openness. Policies are now most clearly available through computer networking. New software are being developed to store employee data, evaluate various information and utilize them for organization.

\section{Integration and Implementation of HRD Sub-systems}

There is very little research conducted on integrated HRD systems. In fact very few organizations seem to have such integrated HRD systems. The indications received by the researchers form the HRD departments of some of the Pharmaceutical companies, public sector companies and scientific goods industry confirm the view that only some of the HRD sub-systems are applied in these organizations. Surely, there are linkages between various subsystems of HRD. Synergistic effects of HRD systems can be obtained only when all the subsystems and their linkages are established. For example, performance appraisal could help in training, OD, career planning and development, job rotation and rewards.

Various case studies are available in the literature about the introduction of HRD Systems in the Indian organizations. Pareek and Rao (1981) and Jain (1996) have presented their experiences of a public sector organization in introducing an HRD system. Gupta and Gangotra (1986) has presented case studies of integrated HRD systems in their respective organizations.

Jain (1996) in his study has highlighted that there exists positive correlation among all the HRD subsystems in BHEL and NFL studied by him. It shows that the HRD sub-systems are closely related and there is need to implement them in an integrated manner.

There is an urgent need that the Indian organizations should make an all out effort to implement HRD as an integrated system. The academicians and researchers in this field can be used to develop the strategies to implement the same. It will help the organization to develop a strong bond among its human resources.

\subsection{HRD Climate in Indian Organizations}

Recognizing the need for studying the HRD process and climate variables the XLRI centre for HRD has developed a 38-item HRD climate survey questionnaire. This questionnaire measures various HRD climate dimensions termed as OCTAPAC culture (openness, collaboration, trust, autonomy, pro-activity, authenticity and confrontation), top management commitment, risk taking, objectivity in rewards and perceived effectiveness of various HRD subsystems in generating a development climate.

Rao and Abraham (1986) surveyed the HRD climate of 41 organizations covering 1,614 respondents. Since the questionnaire used a five-point scale, average scores of 3 and around indicate a moderate tendency on that dimension existed in the organization. Scores around 4 indicate a fairly good degree of that dimension existing in the organization. In order to make interpretations easy the mean scores were converted into percentage scores using the formula Percentage Score $=($ Mean Score -1$) \times 25$.

There are two types of interpretations that could be made for the score of any given organization:

(1) Theoretical Interpretation

(2) Comparative Interpretation

\section{Theoretical Interpretation}

For this interpretation the organization should have its item-wise means or percentage scores and total score. The mean scores for each item could theoretically range from 1.0 to 5.0 where 1.0 indicates extremely poor HRD climate and 5.0 indicates extraordinarily good HRD climate on that dimension. Scores around 3 
indicate an 'average' HRD climate and scores around 2 indicate a poor HRD climate on that dimension. Scores around 4 indicate a good HRD climate where most employees have positive altitudes to the HRD policies and practices of the organization on that dimension and thereby to the organization itself. Mean scores around 4 are indicative of an HRD climate at a desirable level.

Similar interpretations could be offered for percentage scores. In the survey conducted by the HRD centre only eight companies scored above 60 per cent on their overall (general or total) HRD climate scores. Another eight companies scored even less than 50. None scored 75, indicating that there is a good degree of improvement desirable in our organizations.

\section{Comparative Interpretation}

In comparative interpretations the interpreter's interest would be mainly to assess how his company scores in relation to other companies. It is advisable to compare scores on each item. This requires the availability of company-wise scores. The centre for HRD at XLRI supplies the company-wise score without revealing the names of any companies. The following were some of the trends in HRD climate as observed from the survey.

1. The general HRD climate in the organizations surveyed appeared to be at average level (percentage score $=$ 54). There is a good deal of scope for improvement.

2. The most important factor contributing to this seems to be a general indifference on the part of employees to their own development through making efforts to recognize their strengths and weaknesses.

3. The top management in most organizations is seen as doing usual things and do not seem to go out of their way to improve the quality of work life.

4. Lack of support to employees returning from training programmes to implement what they have learnt and not helping in career development was observed.

5. On the positive side employees seem to take training more seriously than their sponsors. A percentage score more than 60 was found on items: top management's belief about the importance of human resources; general helpful nature of employees; fairly objective performance appraisals and promotion decisions; and tolerance for mistakes.

Larsen and Toubro Ltd. keep conducting periodically surveys about HRD climate (Pereira, 1981). State Bank of Patiala is one organization that has surveyed the HRD climate before some of the HRD subsystems were introduced and resurveyed the climate with a gap of about one and a half years.

Jain (1996) studied HRD climate in BHEL and NFL at Top, Middle and Lower levels and ascertained that moderate to Good HRD climate exists in these organizations at all levels in both the organizations. The average scores ranged between 60.00 to 74.00 per cent in these organizations. Recently, another study was made by Jain (2011) for HRD Climate in Scientific Instruments Industry also affirmed this view. The average score in the Industry was 70.25 .

The studies made by the researcher in MNCs, pharmaceutical industry, scientific goods industry and private and public sector organizations show that there appears to be desirably good developmental climate in these organizations. In some of the cases, this observation is derived on the basis of work culture of these organizations, commitment of employees, their satisfaction etc.

It can be concluded that there is possibility of improvement in the developmental climate in the Indian organization which requires an integrated effort on the part of the top management to implement HRD subsystems whole heartedly.

\subsection{HRD Outcomes}

A number of HRD processes like role clarity, increased communication, clarification of norms and standards have been reported in some of the organizations including Indian Oil Corporation, Larsen and Toubro Ltd., Crompton Greaves Ltd., State Bank of India, and SAIL.

HRD outcome variables like improvements in competencies of employees, work commitment, job involvement, organizational health and job satisfaction have not been studied in the context of HRD. Little effort has been made by the academicians in this regard. Jain (1996) has made analysis of the impact of HRD sub-systems on individual efficiency, organizational efficiency and productivity. He has also shown the relationships of HRD sub-systems with HRD climate in BHEL and NFL. These relationships show that there is positive and significant relationship in HRD Climate and productivity, individual efficiency and organizational efficiency. But on the whole, little effort has been made in this direction. It is because of the fact that even leading Indian organizations do not take invest their efforts in management research. HRD systems are applied in their organizations more on the basis of their conviction rather than on empirical evidence.

Organizations should spend at least a small part of their time and other resources to study the changes in their HRD variables. This will help the organization to achieve their goals more effectively. 


\section{Findings of the Study}

The main findings of the study which answers the questions raised in the hypothesis are:

1. The Indian Organizations normally attach significance to the Human Resources and the top management seems to be concerned about the development of its human resources. It is evident from the fact that a number of organizations have established separate HRD department and are applying certain HRD mechanisms in their organizations.

2. The main HRD subsystems being applied in these organizations in India include Performance Appraisal, Training, counseling, rewards, career development etc. Some of the organizations also use OD and HRIS. However, Potential Development is not practiced in its true spirit.

3. The most important factors contributing to the HRD climate seems to be a general indifference on the part of employees to their own development through making efforts to recognize their strengths and weaknesses, employees taking training more seriously, top management's belief about the importance of human resources, general helpful nature of employees, fairly objective performance appraisals and promotion decisions and tolerance for mistakes.

4. The general HRD climate in the organizations surveyed appeared to be at desirably good. On the whole, there existed a good scope for improvement of HRD climate in Indian organizations.

5. As indicated above, a small effort has been made to study the impact of HRD variables on organizational growth, productivity and effectiveness. However, the studies show a positive and significant relationship among the HRD Sub-systems, climate variables and efficiency and productivity.

\subsection{Suggestions}

The following suggestions can be given to strengthen the development of human resources in the organizations:

- HRD System should be introduced in the organizations as an integrated system as the various HRD subsystems are interlinked.

- The organizations should pay more attention on the competency development of the employees

- Periodic reviews should be made to analyze the changes taking place in the organization and to take corrective measures.

- Experimental studies be undertaken to investigate the effectiveness of various HRD practices.

- HRIS should be strengthened to keep up to date information of each employee and to enable the management to use them for employee development and growth.

\section{References}

[1] Anandran K.S. Present Status of HRD in India: Pune Industries. Paper presented at the XVIII, National Convention of ISTD, Bombay, January 1987.

[2] Basu, Mihir K. (1985) Performance Appraisal in India, Centre for Organization Development, Hyderabad (Mimeographed), February.

[3] Chandrasekar, S. (1986) "Computerised Human Resources Information System.” in T.V. Rao and D.F. Pereira (eds.) Recent Experience in HRD. Oxford and IBH Publishing Co. Pvt. Ltd., New Delhi.

[4] D’Souza, Keith. (1986) "A Critical Look at Training in Industry.” in Indian Journal of Training and Development, January-March.

[5] Gupta R. and Gangotra V., (1986) "OD in a Marketing Office”, in Rao, T.V. and D.F. Pereira (ed). Recent Experience in Human Resources Development, Oxford \& IBHPublishing Co. Pv1. L.td., New Delhi.

[6] Jain, V.K. (1996), HRD Practices in Indian Industries, Anmol Publications Pvt. Ltd., New Delhi.

[7] Jain, V.K. (2013) "HRD Climate Factors in Indian Industry- A Case Study" International Journal of Development Research, Vol. 3, Issue, 12, December

[8] Jain, V.K. (2014) "Performance Appraisal as a Sub-system of HRD - A Case Study" in IOSR Journal of Business and Management (IOSR-JBM), Volume 16, Issue 1, Ver. VII, Feb.

[9] Jain, V.K., (2011) "Human Resource Development Practices in Small Scale Industry in India", in Maheswari, S. and Marcarenhas, M. Changing Dynamics of Human Resources (ed.), Excel India Publishers, New Delhi.

[10] Kar, A.B. (1985) Integrated Training Methodology in Industry, Indian Management, July.

[11] Nadler, Leonard (1984) The Handbook of HRD, John Wiley and Sons, Inc.

[12] Pareek, U., Padaki R. Nair RR, (ed) (1992) Managing Transition: The HRD Response, Tata McGraw Hill Publishing Co. Ltd., New Delhi.

[13] Pareek, Udai (1975) “The Concept and the Process of Organization Development.” Indian Journal of Social Work 36(2) (revised)

[14] Pereira, D.F. (1985) Study of Organizational Climate at L \& T. Paper presented at ISTD National Seminar.

[15] Philip J. (1987) "Human Resources Development: Concepts and Practices". In Madras Management Association (ed.) Human Resources Development: Concepts and \& practices.

[16] Rao T.V. and Pareek, U. (1992)Designing and Managing Human Resource System, Oxford \& IBH Publishing Co. Pvt. Ltd., New Delhi.

[17] Rao, T.V. (1984) "Role of Training in Human Resources Developments." in Indian Journal of Training and Development, pp. 118122, July-September.

[18] Rao, T.V. (1986) “HRD: Expecting Too Much, Too Soon.” Business India, Jan.

[19] Rao, T.V. HRD (1990)Missionary Oxford \& IBH Publishing Co. Pvt. Ltd., New Delhi.

[20] Rao, T.V. (1991) Readings in Human Resource Development Oxford \& IBH Publishing Co. Pvt. Ltd., New Delhi. 
[21] Rao, T.V. and D.F. Pereira (ed). (1986) Recent Experience in Human Resources Development, Oxford \& IBH Publishing Co. Pv1. L.td., New Delhi.

[22] Rao, TV. (1982) "HRD Practices in Indian Industry". Lok Udyog, March.

[23] Rao, TV. and E. Abraham (1986) "HRD Practices in Indian Industries: A Trend Report." Vol. 11, Vol.2: Management and Labour Studies, April.

[24] Sahni, Ashok (1984) "Career Planning for HRD and Utilization.” Indian Management, June.

[25] Singh, Ramadhar. (1983) "Management of Reward system.” IIM, Ahmedabad.

[26] Sinha, Dharni (1986) T-Group, Team Building and Organization Development, ISABS, New Delhi. 